ISSN1331 - 677X (UDK 338)

May $30^{\text {th }}$ - June $1^{\text {st }} 2013$

\title{
UNEMPLOYMENT AND SELF-CONCEPT
}

\section{Tjaša Redek, Andrej Sušjan ${ }^{b}$ Črt Kostevcc}

${ }^{a}$ Associate Professor, Ph.D, Faculty of Economics, University of Ljubljana, Kardeljeva ploščad 17, 1000 Ljubljana, Slovenia, tjasa.redek@ef.uni-lj.si.

'Full Professor, Ph.D, Faculty of Economics, University of Ljubljana, Kardeljeva ploščad 17, 1000 Ljubljana, Slovenia, andrej. susjan@ef.uni-lj.si.

'Associate Professor, Ph.D, Faculty of Economics, University of Ljubljana, Kardeljeva ploščad 17, 1000 Ljubljana, Slovenia, crt.kostevc@ef.uni-lj.si.

\section{ARTICLE INFO}

Keywords:

- ageing,

- age discrimination,

- self-concept,

- unemployment persistence

\section{ABSTRACT}

The article analyses the position of the unemployed in the labour market, primarily relationship between self-concept and self-esteem of workers and their motivation to seek work. The current crisis dramatically worsened labour market situation, making employment almost impossible for many, primarily the vulnerable groups (older, women). Survey data used in cluster analysis reveal that the unemployment is related to self-concept, but besides unemployment also other factors, primarily age, and sex matter. Also, the reactions of people to unemployment conditional on their self-concept differ.

Reference to this paper should be made as follows: Radek T, Sušjan A, Kostevc Č,. 2013. Unemployment and self-concept, Ekonomska istraživanja - Economic Research Special Issue 2013 


\section{INTRODUCTION}

Self-concept describes the image one has of him/herself. This image evolves continuously and changes subject to external and internal factors one is exposed to. When speaking about people, age determines important vector of our self-concept. Namely, age is one of the most defining elements of our lives. According to Sargent (2006) it determines when we go to school, we are allowed to drive, marry, retire and a number of other things. Unfortunately, age is also linked with a number of stereotypes. The young are careless, bold, driven, while the old are unproductive, sickly, and inflexible. The question is, whether such ageism or stereotyping affects us and our behaviour, our reactions in the situations we are exposed to. It would be hard to argue that we do not feel at least some pressure to prove that we are not what the (usually negativistic) stereotypes claim us to be. If this is true, then our self-concept is affected by the stereotypes. And if Franken (1994) is right claiming that self-concept is elementary for the direction of our motivation, then also ageism (or any other stereotyping we take to heart) will affect us.

The discussion of the self-concept is very important for the labour market and the behaviour (and employment) of the disadvantaged groups (women, young, old, disabled, foreigners). Unemployment in general damages self-concept and self-esteem. This lowers people's motivation to seek work, which further damages their self-concept and lowers motivation to seek work with time. And lack of success or constant failure in seeking work damages their self-concept even more. Until many of them exit the labour market. And the labour market exit is not the only negative consequence, constant failure is associated with stress and other health issues which lower the quality of life and further damage the potential to work (Linn et al., 1985, Winter, 1997, Smith and Segal, 2013). The responses of individuals to unemployment conditional on their self-concept differ by not only the attained self-concept (self-esteem) level, but self-concept is also affected by other variables, like the duration of unemployment, sex, age, etc.

We investigate the self-concept of the unemployed, primarily with the focus on age. Why age? The recent crisis blurred the relative disadvantage of the elderly as the news often focus on the lack of employment chances of the young. In fact, the crisis deteriorated the position of the older $(50+)$ workers in Slovenia, their share increased by 10 percentage points to 35 percent of total unemployment between 2006 and 2011 (Zavod za zaposlovanje RS, 2012). Also, the crisis will not change the process of ageing of the European population. By 2060 European population (EU27) will change significantly in both size and structure. Median age is expected to rise from 40.4 years (2008) to 47.9 years (2060). Those, aged 65 or more, will represent $30 \%$ of total population compared to 'just' $17.1 \%$ in 2008 (Eurostat, 2011). Consequently the position of the older workers can hardly be expected to improve. Especially since the employers often prefer the young. Roscigno et al., 2007, Schwarz-Woelzl et al. (2008), Hutchens, 1988 and other). Therefore the motivation of the older to seek work and confidence in themselves are extremely important for their success in the labour market.

Linking the concepts of ageism, age discrimination, self-concept, self-esteem and labour market builds the main hypothesis of the article: Unemployment harms individuals' self-concept. The hypothesis has three sub-hypotheses: (1) Duration of unemployment is negatively related to self-concept. (2) Self-concept is further harmed by potential or perceived discrimination (age, women). (3) Factors that negatively impact the self-concept of the unemployed, negatively impact their motivation to seek work and their physical and mental status. The analysis is based on 2009 survey data among the unemployed'. To check the hypotheses clustering method is used.

The structure of the article is as follows. We first provide a definition of the self-concept and link 
the concept with age discrimination in order to determine the theoretical foundation for the hypotheses. Second, we provide a description of the methodology and descriptive statistics. Last we use cluster analysis to examine the hypotheses. In conclusion the results are discussed.

\section{SELF-CONCEPT}

When studying attitudes of people towards a specific problem or issue, a multilevel approach should be taken. To analyse the position of workers in the labour market, we rely on Berger (2006), who stresses the triangular linkage among identity, work and age. Usually, as he says, theory linked identity and age and separately also identity and work. But the three elements should be analysed together in order to understand fully the individual's motives, attitudes and motivation in the process of seeking work. We stem from this generalized approach and use psychological constructs of self-concept and self-esteem for a more detailed comprehension of the nature of life choices.

Self-concept is the sum of individual's beliefs about himself, including his attributes and who and what the 'self' is. It comprises also the well-known self-esteem which is deepest personal self-evaluation in different areas of life (Baumeister, 1999: 247-248). As psychologists show, the development of self-concept begins already in very early childhood and continues to evolve intensely during adolescence and later during career development and private life (e.g. Kagan, 1981, Sebastian et al., 2008). It is important to add that self-concept develops a lot due to interactions with others. As Luke (2011) claims, because humans are social creatures, they develop an understanding of themselves as a result of their relationship with the people they come in contact with.

The self-concept and self-esteem are relevant for what we do and how we perform in life in general, which includes our careers. For example, research shows that high self-esteem is good. High academic self-esteem is related to good academic results (Peralta Sanchez et al., 2003). Gattiker and Larwood (1986) show that career success depends on employee's perception of occupational self-concept among other variables. According to Powell (2009) self-confidence is especially important for women in executive positions since it helps them overcome the additional sex-related burden. Modupe (2010) goes even further and stresses the 'need to foster in persons positive self-concept and self-esteem as panacea for industrial development' by linking the self-concept with industrial organization and productivity ${ }^{2}$.

What does self-concept imply for career choices or success? In line with the Lent, Brown and Hackett's social cognitive career theory (1987) (in continuing 'SCCT' theory) career choice depends on 4 major factors (personal performance accomplishments, vicarious learning, social persuasion and physiological states and reactions) that work through a self-reinforcing process. Success in this career (life) process depends largely on how individual's work is successful and provides also valued compensation. According to this theoretical approach the perception of barriers one faces is also important: high (perceived) barriers are expected to cause weaker motivation and impact the course of action.

\footnotetext{
${ }^{1}$ The survey was carried out in 2009. Despite the time lag we believe that the results are still relevant as the behaviour and the perception of one-self in relative terms (to other parts of population) is less under the impact of the size of the unemployed pool than it is under the influence of the relative position of an individual. Of course, the absolute values of the results could be impacted. But the relationships tested could be rationally expected to hold also today.

${ }^{2}$ But it must be acknowledged that despite the fact that people with high-self esteem are better off than people with low, the high self-esteem might not be based on actual better quality (Baumeister, 2003, p.259).
} 


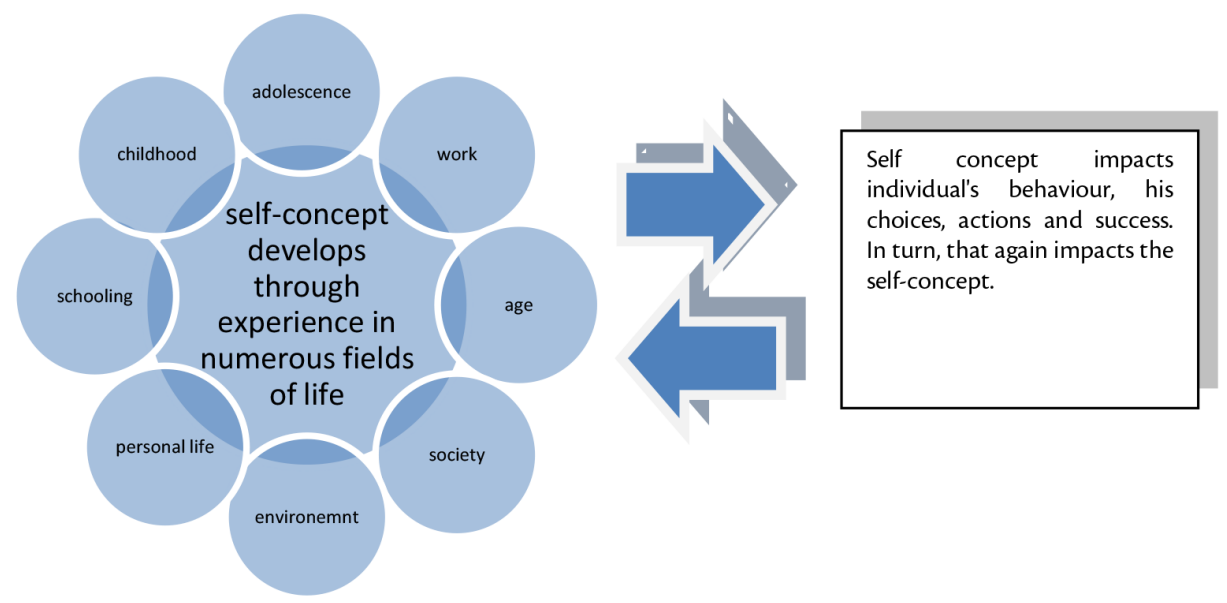

Source: Authors' own, 2013

\section{FIGURE 1. SELF-CONCEPT}

The problem is highly relevant in the labour market. The unemployment and perceived (or actual discrimination) each separately or together (even more) impact one's self-concept.

Unemployment (or long-term unemployment even more) as the final step of (momentary) career failure has numerous consequences, both psychological and material. To mention just a few: Moore and Waters (2001), for example, show that employment status significantly predicts self-esteem and depressive effect, which is related also to consequential material deprivation. Similarly, other psychological research shows that unemployment has significant personal consequences, ranging from emotional distress, anxiety, depression (Smari et al., 1997, Grossi, 1999). Elmslie and Sedo (1996) link discrimination and the concept of learned helplessness to show how discrimination creates helplessness, which negatively impacts individual's human capital and thereby lowers future chances of finding work. But interestingly, stronger motivation to seek work can cause also a stronger depression in case of failure, as was argued by Feather and Davenport (2002). Given that the perception of unemployment in society depends on culture and specific moment in time, any results can hardly be generalized.

Additionally, age discrimination also impacts self-concept. Redman and Snape (2006) consider the psychological consequences of perceived age discrimination among police officers and the role of social support. They show that age discrimination is a stressor; it impacts negatively job and life satisfaction, perceived power and prestige on the job and affective and normative commitment. Tougas et al. (2004) analyze the consequences of age discrimination and ask 'what are the consequences for aging workers of integrating into their self-image some of the characteristics commonly associated with their cohort'. The conclusion is that the more individuals adopted the characteristics prescribed to older workers, the more they felt deprived, which led to lower selfesteem and life satisfaction. Also the much less problematic ageism can pose a serious threat to the self-concept. If stereotypes in the society are strong, individuals are much more aware of them and thus stereotypes alone can cause him/her to feel discriminated.

In addition to employment, age, also sex contributes a part of the explanation. Although caution is required when acclaiming part of the differences also to gender, as Wigfield et al. (2002) 
claim, since intragroup differences are often bigger as between-group differences, gender nonetheless does contribute a part of the explanation. The authors' review work shows a lot of variability in terms of gender differences, but at the same time they find substantial amount of literature in support of the fact that young women have a lower work self-esteem than men and that they are more likely to develop serious under-evaluations and health-risk (Wigfield et al, 2002, p. 12). Zuckerman (2006) empirically examined a sample of close to 900 individuals and found a relationship between self-esteem, better self-concept and attainment, although results differ by sub-groups. But for example, the 18-25 year old men described themselves more often as attractive, which was also related to their higher educational and career choice. A variety of literature reflects the fact that sex self-concept is related to career choice (Wigfield et al., 2002, Zuckermann, 2006, Moreland et al., 1978) and other (Wigfield et al, 2002, Zuckerman, 2006). There is also a vast literature relating poor self-concept to depression, vulnerability and gender, although the evidence is not clear as was shown in a vast meta-analysis conducted by Swislo and Orth (2012). But when only depression is considered, medical studies show that women are much more likely to face depression (even twice) than men (Noel-Hoeksema, 2001), Piccinelli and Wilkinson (2000). But when studying the impact of unemployment on mental health, Artazcoz et al. (2004) find that the effect of unemployment on mental health depends also on gender, family responsibilities and social class (this could potentially be generalized to health).

In addition to the variables mentioned, other elements also impact self-concept of an individual. For example, cultural element is important, as studies show culture impacts the way individuals describe themselves (for example see Kashima et al., 2011). Also, culture impacts the perception of employment or unemployment as a problem (or not), therefore a comparative study in this context would be very interesting (see for example Maddux and Yuki, 2006). Other variables could also be studied, like family, education, life-experience, social factors, income, and a number of others (for factors impacting self-concept see Franken, 1994, or Baumeister, 1999).

This theoretical discussion shows that the discussion on the relationship between unemployment, self-concept, and reactions to unemployment is wide and that the results differ. Nonetheless, there is evidence in support of our hypotheses. In short, we examine the self-concept of the unemployed, examine the 'demoghraphics' of the groups and the differences in reactions to the problem of unemployment between the two groups.

\section{METHODOLOGY}

The study is based on survey data, carried out in April 2009 among the unemployed in all Slovenian regions with the assistance of 'Employment service of Slovenia'. 1000 questionnaires were distributed; the response rate was $37.1 \%$.

The questionnaire comprised 3 parts. One part was examining the general characteristics of the respondent (age, sex, duration of unemployment, number of applications for work, education, occupation, marital and family status). The respondents were asked to evaluate a number of statements about the labour market, which were Likert scale type questions. Also, a set of questions was aimed at examining the self-concept of the individual ${ }^{3}$, responses and reactions of the individual in job search and impact of failure on the individual. In total, the questionnaire comprised 10 questions with sub-questions and 7 demographic questions with sub-questions.

\footnotetext{
${ }^{3}$ The variables were selected based on our previous reseach experience (Domadenik et al., 2008).
} 
The sample of unemployed consisted of 371 people, 127 men and 241 women ( 3 did not provide information on their sex). The average age of the respondents was 37.36 years, 37.55 for men and 37.32 for women. 84 respondents were aged 50 or more, the average age of the older group was 54.33 years. 283 respondents were aged 49 or less, the average age in this age group was 32.34 years $^{4}$. The structure of the sample is skewed towards the young.

The majority of the respondents has finished secondary schooling ( $41.8 \%)$, followed by those with 'professional training degree' (14.3\%), those with the university degree $(13.2 \%)$ and those with only primary degree or even less (11.6\%). The differences in educational attainment among the two age groups are only slight; the biggest difference is in the share of those with secondary diploma, which is bigger among the younger group $(43.1 \%)$ than the old (38.1\%). But cumulatively in both age groups around $75 \%$ of the respondents have secondary schooling or less.

Empirical analysis will be based on cluster analysis, in order to obtain groups with similar selfconcept. Differences between groups will be studied based on appropriate statistical tests ( $t$-test, analysis of variance, F-test, Chi-square, depending on data type).

\section{RESULTS}

The theoretical approach claims that self-concept is linked to a number of consequences for an individual, primarily motivation to seek work and also health. In order to investigate the relationship of the self-concept to other variables in question, we first define the 'self-concept' variable. For empirical purposes of the analysis, we limited the self-concept variable to the aspects that are most relevant for individuals' employability. Thus a number of variables that in fact do impact personal happiness were omitted due to the limitations of the questionnaire (satisfaction with partnership, family, relative poverty, weight issues, genera success in life, etc.).

Each individual was asked to evaluate him-self/her-self in a series of 22 aspects that are relevant for their employability and work performance (like motivation, computer, language skills, loyalty, honesty, etc.). The values spanned on a standard Likert 1-5 scale, 1 meaning 'not good', and 5 denoting that individual is 'very good' in a specific aspect. For each individual also the value of the 'self-concept' variable was defined as an average of all 22 aspects. Figure 1 reveals the descriptive statistics. On average, the sample is most confident in their honesty, reliability, team-work skills, motivation and loyalty. They were most reluctant to admit their clumsiness, and they were not confident in their foreign language skills, career development so far, physical power and computer skills. Given that the self-concept variable was defined as the average value of the variables in question for each individual, the actual self-concept is also somewhere in the middle.

\footnotetext{
${ }^{4}$ The sample is somewhat imbalanced with a significantly larger share of younger respondents. In April 2009 there were 82832 unemployed (registered). 25079 were aged 50 or more, which is $30.2 \%$ of total. The sample comprises of 371 people, 84 or $22.6 \%$. Unfortunately, the older are harder to reach and even less willing to cooperate than the young. Nonetheless, the results are indicative to general situation and are in line with what is expected given the situation in Slovenia. Therefore we feel that this imbalance does not significantly impair the validity of results (Data from Employment service of Slovenia, 2011).
} 


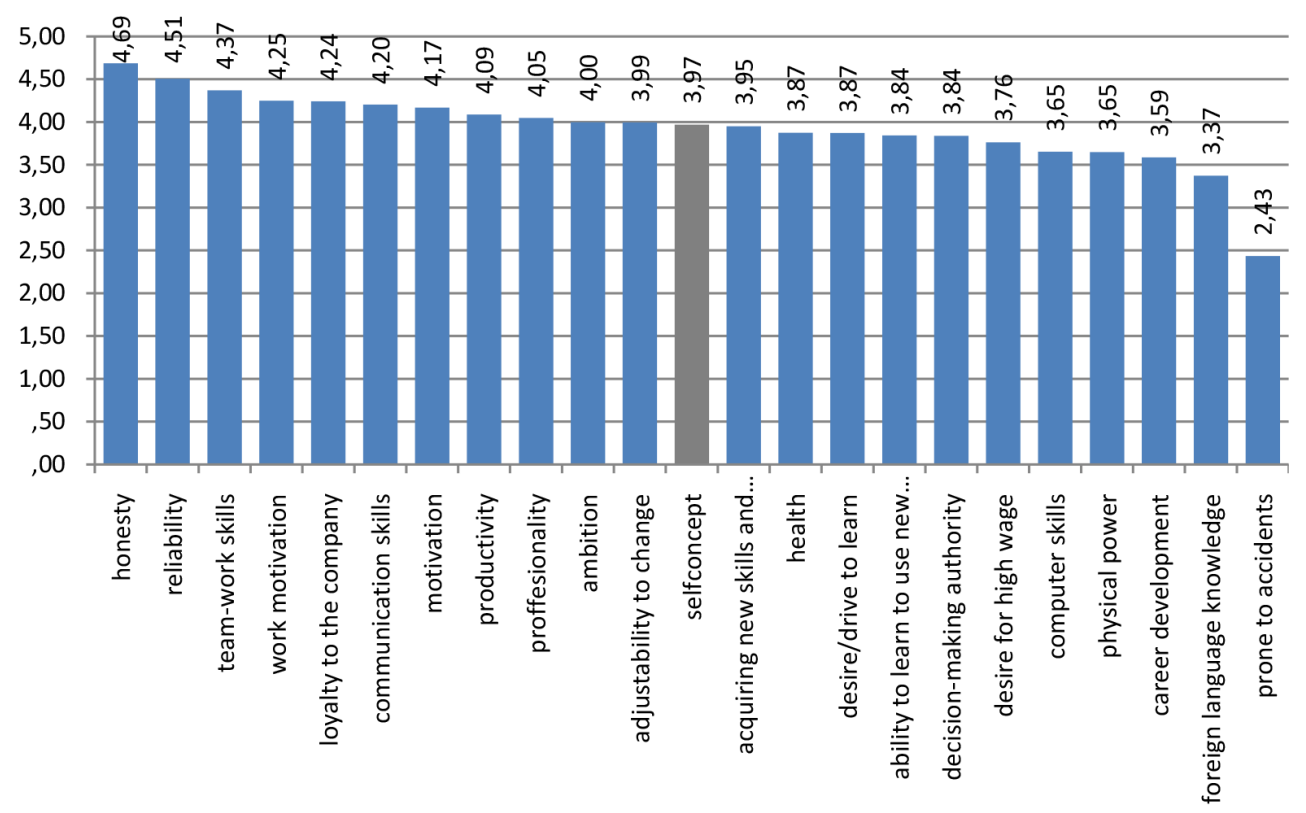

Source: Research results, 2013

In order to test the differences between groups of unemployed with poorer and better selfconcept, we use clustering analysis based on the 22 variables (not the self-concept variable, this is an average, thus it is excluded to avoid double inclusion). Based on the Ward method hierarchical clustering due to the nature of the clustering variables 2 clusters were obtained. In total 305 individuals were clustered into two groups (the rest were due to missing variables excluded). The two clusters differ significantly in the perception of the self-concept of the individuals. Table 1 provides descriptive results by cluster.

Table 1 reveals the evaluation of self-concept elements by cluster, the overall value of the self-concept variable and the statistical significance of the differences. Except for the case of the 'accident prone' variable, the differences are significant in all other cases. This is also the only example, in which the second cluster is worse, meaning that they claim to be less accident prone. The differences between the two clusters are most eminent in the following cases: foreign language knowledge, career development, ambition, acquiring new skills, desire/drive to learn. 
Tjaša Redek, Andrej Sušjan, Črt Kostevc

TABLE 1-VARIABLES DETERMINING SELF-CONCEPT BY CLUSTER

\begin{tabular}{|c|c|c|c|c|c|}
\hline & Cluster & $N$ & Mean & $\begin{array}{c}\text { Std. Error } \\
\text { Mean }\end{array}$ & $\begin{array}{c}\text { T-test, equal vari- } \\
\text { ances not assumed, } \\
\text { sig.level }\end{array}$ \\
\hline \multirow{3}{*}{ Acquiring new skills and knc } & 1 & 63 & 3,10 & 100 & \\
\hline & 2 & 242 & 426 & 047 & Oח0 \\
\hline & & & & & \\
\hline \multirow[t]{2}{*}{ Desire/drive to learn } & & 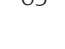 & , OL & 20 & \\
\hline & 2 & 242 & 4,19 & ,051 & ,000 \\
\hline \multirow{3}{*}{ Ability to learn to use new t } & 1 & 63 & 2,92 & 116, & \\
\hline & 2 & 242 & 415 & & م०0 \\
\hline & & & & & \\
\hline \multirow{3}{*}{ Computer skills } & 1 & 63 & 2,83 &, 140 & \\
\hline & & & & & \\
\hline & 2 & 242 & 3,95 & ,057 & ,000 \\
\hline \multirow{3}{*}{ Work motivation } & 1 & 63 & 3,67 & , 106 & \\
\hline & & & & & \\
\hline & 2 & 242 & 4,47 & 040 & ,000 \\
\hline \multirow{2}{*}{ Productivity } & 1 & 63 & 3,33 & 101 & \\
\hline & 2 & 242 & 4,32 & 041 & 000 \\
\hline \multirow{2}{*}{ Reliability } & 1 & 63 & 3,94 & 117 & \\
\hline & 2 & 242 & 4,73 & ,032 & 000 \\
\hline \multirow{3}{*}{ Physical power } & 1 & 63 & 2,92 & ,118 & \\
\hline & & & & & \\
\hline & 2 & 242 & 3,86 &, 058 &, 000 \\
\hline \multirow[b]{2}{*}{ Adjustability to change } & 1 & 63 & 3,25 &, 113 & \\
\hline & 2 & 242 & 4,29 &, 047 &, 000 \\
\hline \multirow{3}{*}{ Prone to accidents } & 1 & 63 & 2,54 &, 115 & \\
\hline & & & & & \\
\hline & 2 & 242 & 2,36 &, 073 & 199 \\
\hline \multirow{3}{*}{ Proffesionality } & 1 & 63 & 3,16 &, 111 & \\
\hline & & & & & \\
\hline & 2 & 242 & 4,31 & 046 & ,000 \\
\hline \multirow{3}{*}{ Health } & 1 & 63 & 3,14 & ,132 & \\
\hline & & & & & \\
\hline & 2 & 242 & 4,20 & ,054 &, 000 \\
\hline \multirow{3}{*}{ Decision-making authority } & 1 & 63 & 3,03 & ,099 & \\
\hline & & & & & \\
\hline & 2 & 242 & 4,11 & ,048 & ,000 \\
\hline
\end{tabular}




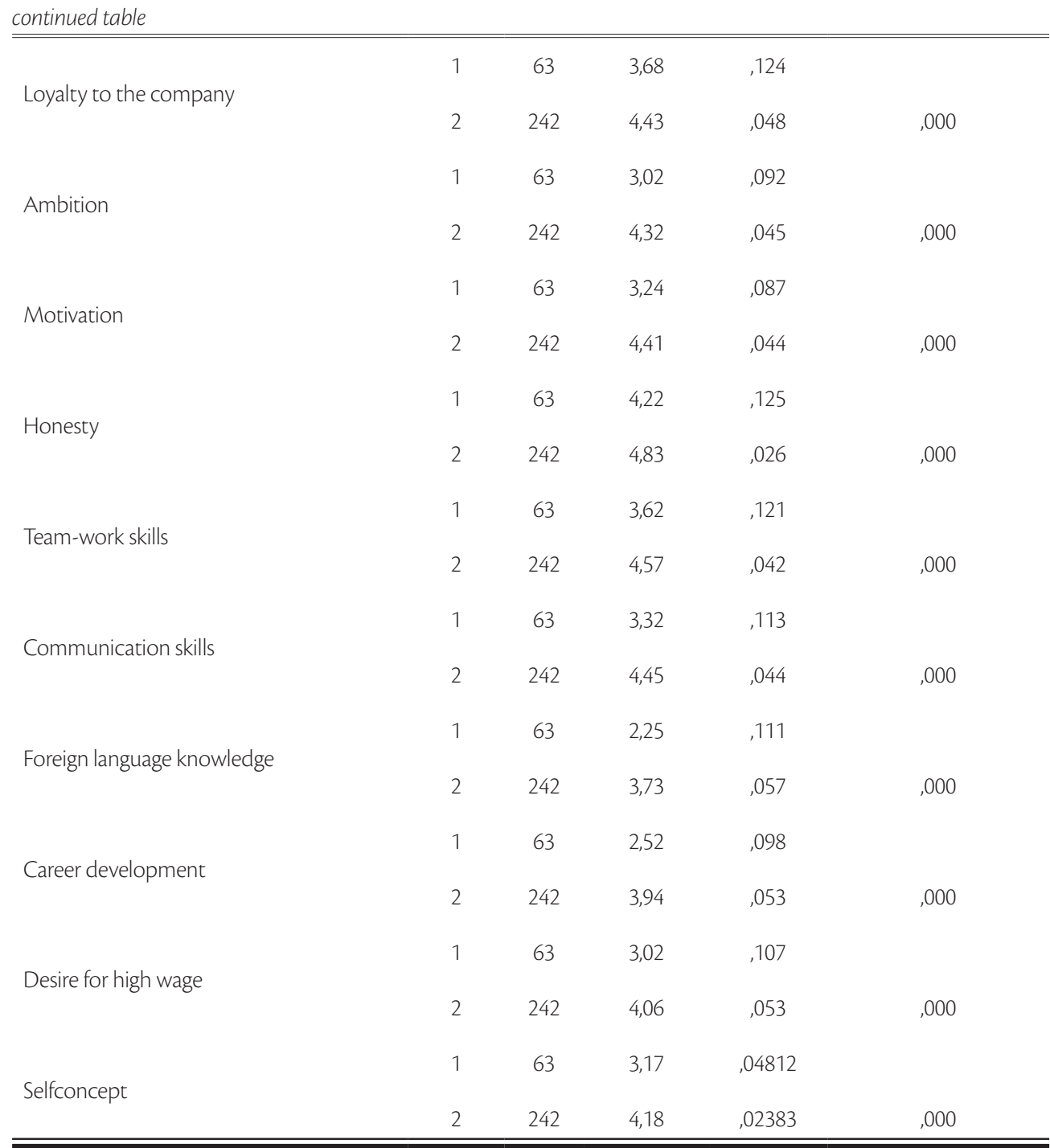

Source: Research results, 2013

Given our hypotheses, it would be expected that the two clusters differ significantly by unemployment length and other characteristics (age, sex, experiences in the labour market). In the first cluster, the average age of the respondent was 42.7 years, while in the second cluster the average age was 34.7 years, which is statistically significantly $(p=.000)$ less. The first cluster is the 'old' cluster, which supports the thesis that age is related to self-concept (although could be caused also by age-related experiences in the labour market, which we examine in continuing). Given the age difference between the two clusters it can be expected that the first cluster will have more working experience, which is also revealed by the data. The work experience of the first cluster exceeds the work experience of the second cluster by roughly 30 percent. The two cluster differ slightly also in sex structure. 43 percent of 'cluster 1' were men and 32 percent of 'cluster 2' were men. The data seems to indicate (although not significant) that sex also has an impact. In accordance with our previous research (Redek and Sušjan, 2011), men did evaluate themselves poorly, 
but this was noticed primarily in older men's case. The reasoning is that men have to work longer to achieve the pension age. Consequently, they are more likely to have less success and face more challenges, be also more likely to face age discrimination (or perceive it), which can impact their self-concept. But the two clusters do not differ significantly by the average duration of unemployment. In the first cluster individuals were on average unemployed 19 months, while in the second cluster 18 months. Even among the young there are quite a few cases reporting to be unemployed since out of school (for even 5 years at age of 24). The longest unemployment durations have been provided by the old of close to 60 years: in total 10 years of unemployment or 9,7 years or 9 years; all cases are from Maribor, ex industrial centre. But on the other hand the activity in the second cluster aimed at solving the unemployment issues was more pronounced (Table 2). On average, they sent out significantly more work applications that the members of the first cluster. This does speak in favour of the hypothesis that poor self-concept leads to lower motivation to seek work. Also, it should be noted that the members of the first cluster are on average older and consequently the continuous failure (for even 10 years) does leave a strong mark on an individual. Labour market activity is evident also from the question about changing jobs: young are more prone to switching, which could be caused either by the supply (fixed-term contracts) or demand (more flexibility by the young).

TABLE 2. JOB APPLICATIONS BY CLUSTER

\begin{tabular}{|c|c|c|c|c|c|}
\hline & Cluster & $N$ & Mean & $\begin{array}{l}\text { Std. Error } \\
\text { Mean }\end{array}$ & $\begin{array}{c}\text { Sig. } \\
\text { (2-tailed) }\end{array}$ \\
\hline \multirow{2}{*}{ How many times did you change jobs? } & 1 & 54 & 2,31 & ,221 & \\
\hline & 2 & 189 & 2,46 & ,167 & 600 \\
\hline \multirow{2}{*}{$\begin{array}{l}\text { How many job applications did you send } \\
\text { within last month }\end{array}$} & 1 & 40 & 2,93 & ,442 & \\
\hline & 2 & 190 & 7,99 & 1,662 &, 004 \\
\hline \multirow{2}{*}{$\begin{array}{l}\text { How many job applications did you send } \\
\text { within last year? }\end{array}$} & 1 & 17 & 14,06 & 6,799 & \\
\hline & 2 & 82 & 26,80 & 4,117 & 120 \\
\hline \multirow{2}{*}{$\begin{array}{l}\text { How many job applications did you send } \\
\text { prior to last year? }\end{array}$} & 1 & 13 & 10,69 & 3,543 & \\
\hline & 2 & 44 & 33,57 & 9,360 & ,026 \\
\hline
\end{tabular}

So on average, the first of the two clusters is the older cluster and comprises more men (although women dominate both), while the second is the younger cluster even more dominated by women. The first has the poorer self-concept. We investigate now in more detail, how this might be reflected in behavioural differences in the labour market and individuals' health.

Table 3 presents perceptions about the labour market in general and some personal insights. The statements were again 1-5 Likert scale statements. Both clusters agree to a very similar extent that family is an obstacle when seeking work (although in general across the entire sample, not by cluster, women statistically significantly feel family to be more of an obstacle). In terms of the hypotheses and given the clusters' demographic characteristics, the results support the hypotheses. In the first cluster (dominated by older) there is more support to the idea that older 
are less motivated to learn and that this is perceived as an obstacle. Also, the first cluster is less prone to desiring additional training and did not always take the opportunity to be involved in additional training if such an opportunity came. The cluster perceives work more as a necessity (I only work to survive), and are convinced that age is a factor of employment.

TABLE 3. LABOUR MARKET PERCEPTIONS BY CLUSTER

\begin{tabular}{|c|c|c|c|c|c|c|}
\hline & Cluster & $\mathrm{N}$ & Mean & $\begin{array}{l}\text { Std. } \\
\text { Mean }\end{array}$ & Error & $\begin{array}{l}S \text { i } g \\
\text { (2-tailed) }\end{array}$ \\
\hline \multirow{2}{*}{$\begin{array}{l}\text { The older are less motivated to learn, thus the employ- } \\
\text { ers prefer to employ the young. }\end{array}$} & 1 & 62 & 3,48 & 143 & & \\
\hline & 2 & 238 & 3,11 & 077 & & 025 \\
\hline \multirow{2}{*}{ I wish I had more opportunity for on-the-job training. } & 1 & 62 & 3,42 &, 141 & & \\
\hline & 2 & 240 & 4,31 & ,048 & &, 000 \\
\hline \multirow{2}{*}{ In the past I had the opportunity for additional training. } & 1 & 61 & 2,72 & ,177 & & \\
\hline & 2 & 234 & 2,87 & ,091 & &, 451 \\
\hline \multirow{2}{*}{$\begin{array}{l}\text { If I got the opportunity for additional training, I always } \\
\text { took it. }\end{array}$} & 1 & 62 & 3,60 & ,158 & & \\
\hline & 2 & 236 & 4,36 & ,060 & & ,000 \\
\hline \multirow{2}{*}{ My last work environment was nice. } & 1 & 62 & 3,73 & ,144 & & \\
\hline & 2 & 234 & 3,71 & ,080 & & 921 \\
\hline \multirow{2}{*}{ Good work environment is important for motivation. } & 1 & 61 & 4,52 & , 106 & & \\
\hline & 2 & 237 & 4,82 &, 030 & & 010 \\
\hline \multirow{2}{*}{ Companies prefer to employ the young. } & 1 & 61 & 4,16 &, 115 & & \\
\hline & 2 & 238 & 3,74 & ,070 & & 002 \\
\hline \multirow{2}{*}{$\begin{array}{l}\text { Because companies prefer to employ young, I am less } \\
\text { motivated to seek work. }\end{array}$} & 1 & 60 & 3,30 & ,153 & & \\
\hline & 2 & 234 & 2,56 & 087 & & 000 \\
\hline \multirow{2}{*}{ Family is an obstacle in seeking work. } & 1 & 62 & 2,92 & ,155 & & \\
\hline & 2 & 238 & 2,88 & 085 & & ,834 \\
\hline \multirow{2}{*}{$\begin{array}{l}\text { I only work to survive. My job is not motivating and I do } \\
\text { not enjoy it. }\end{array}$} & 1 & 62 & 2,55 & 1,141 & & \\
\hline & 2 & 235 & 2,11 & 1,241 & & ,081 \\
\hline
\end{tabular}

We further investigated the relationship between the self-concept and individual's actions also by examining their reactions to the failure in job-search. The focus of the questionnaire was on age discrimination. Given that age is according to the clustering results a factor of self-concept, we further investigate age related items. In total, out of the 303 respondents that replied to the question whether they believe to have been ever age discriminated, exactly 30 percent of answers were affirmative. The clusters differed. In the first (older) cluster 37 percent of people believed to be compared to 28 in the second (younger) cluster. The result is not significant; the significance level is 20 percent. Nonetheless, it is an indication that age is an issue also due to perceived discrimination.

In line with the discrimination issue, individuals were also asked, how the situation impacts their behaviour and health. Figure 3 reveals the reactions of both clusters to perceived discrimination. 


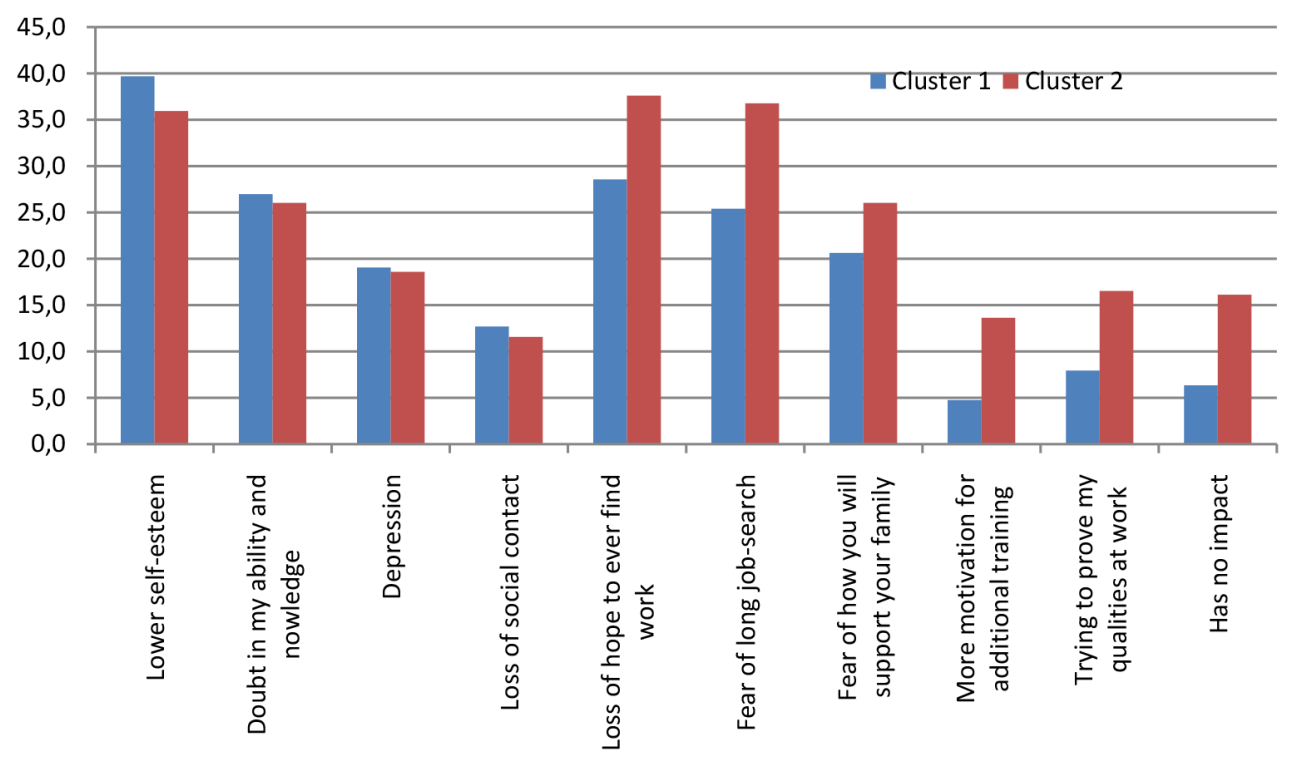

FIGURE 3. REACTION OF BOTH CLUSTERS TO JOB SEARCH PROBLEMS RELATED TO AGE*

Source: Research results, 2013

As percent of people who chose this option. Each respondent was allowed to choose as many consequences as desired.

Data reveal that self-concept is related to different actions in case of unemployment. While both groups are (as expected) affected by low self-esteem, doubt, depression, loss of social network, the second group with better self-concept is more deeply hurt (loss of hope, fear), but at the same time also reacts more aggressively to solve the problem: they are more motivated for additional training and are more prone to trying to prove themselves at work. These results are in line with other empirical studies. While the first cluster comprises more old and more men than the second, it can be expected that age (and potential) age discrimination could be an issue in this cluster. Also the data on the duration of unemployment are an important element of explanation, some people in the group have been unemployed for up to 10 years. Loss of interest, evident from Figure 3 (motivation for additional training, proving your abilities), is more characteristic of this group. They tend to give up.

On the other hand, in line with the findings of Feather and Davenport (2002), stronger motivation can also be related to stronger consequences in case of failure. Figure 3 reveals that cluster 2 on one hand is more motivated to do additional training, to prove themselves in the company, to send out more job applications (Table 2) but on the other hand, it is also evident that they are significantly more afraid of long job search and loss of hope.

Both groups equally report depression, loss of social contact and doubt in their ability. But these results (the equality) should be interpreted with care. The duration and the continuing failure (as in the case of first cluster) culminate in the end in lower self-esteem, poorer self-concept, stronger health consequences, and depression. 


\section{DISCUSSION AND CONCLUSION}

The article provides some insight into the relevance of self-concept in the labour market with the focus on the unemployed.

Linking the concepts of ageism, age discrimination, self-concept, self-esteem and labour market builds the main hypothesis of the article: Unemployment harms individuals' self-concept. (1) Duration of unemployment is negatively related to self-concept. (2) Self-concept is further harmed by potential or perceived discrimination (age, women). (3) Factors that negatively impact the self-concept of the unemployed, negatively impact their motivation to seek work and their physical and mental status. The analysis is based on survey data among the unemployed. To check the hypotheses clustering method is used.

The analysis is based on survey data. The results are in part in line with the hypotheses, but in many cases, further investigation on a larger sample with additional questions would provide better results. For example, regarding the hypotheses, the results show that two clusters are formed. The self-concept of the first cluster is worse. This cluster is on average unemployed for longer, also is older ( $\mathrm{H} 1$ and $\mathrm{H} 2)$. On the other hand, the younger cluster with better self-concept is much more motivated to seek work, but is more afraid of failure $(\mathrm{H} 3)$, which is in line with some other findings. For more reliable results, the analysis should become periodical, if possible capturing the same individuals over a longer period of time. Namely, the impact of failure on self-concept worsens with time.

Despite many limitations of the analysis, the results refer to an important, but often neglected element of the labour market policy. It is important to activate people, not just because of their income status, but primarily because of their self-concept and their future progress in professional field.

In terms of the ageing labour market situation and the growing proportion of the older workers in the market as well as a large and growing proportion of older unemployed, the analysis points to the important consequences of long unemployment periods of older workers, who become discouraged and may leave the work-force. In ageing perspective, this is the least desirable outcome both for the individual and the state. 


\section{REFERENCES}

Artazcoz, Lucía, Benach, Joan, Borrell, Carme and Cortes, Immaculate. 2004. "Unemployment and Mental Health: Understanding the Interactions Among Gender, Family Roles, and Social Class," American Journal of Public Health, 94/1 (204): 82-88.

Baumeister, Roy F. 1999. "Self-concept, self-esteem, and identity". In Personality: Contemporary theory and research, edited by Valerian J. Derlega, Winstead Barbara A. and Warren $\mathrm{H}$. Jones, 339-375. Chicago, IL: Nelson-Hall Publisher.

Berger, Ellie D.2006."Aging' identities: Degradation and negotiation in the search for employment," Journal of Aging Studies, 20/4: 303-316.

Domadenik, Polona, Ograjenšek, Irena, Redek, Tjaša. 2008. Ageing in Slovenia and the European Union: the macroeconomic and the microeconomic perspective. Ljubljana: Ekonomska fakulteta.

Elmslie, Bruce and Sedo, Stanley. 1996. "Discrimination, social psychology, and hysteresis in labor markets," Journal of Economic Psychology,17/4: 465-478.

Eurostat. 2013. "Eurostat on-line database." http://epp.eurostat.ec.europa.eu/portal/page/portal/eurostat/home.

Feather Norman T. and Davenport P.R. 1981. "Unemployment and depressive affect: a motivational and attributional analysis." Journal of Personality and Social Psychology, 41/:422-36.

Gattier, Urs E. and Larwood, Laurie. 1986. "Subjective career success: A study of managers and support personnel," Journal of business and psychology, 1:78-94.

Grossi, Giorgio. 1999. "Coping and emotional distress in a sample of Swedish unemployed," Scandinavian Journal of Psychology, 40/3:157-165.

Hutchens, Robert M. 1988. "Do job opportunities decline with age?" Industrial and labour relations review, 42/1:89-99.

Kagan, Jerome. 1981. The second year. The emergence of self-awareness, Cambridge, MA: Harvard University Press.

Kashima, Emiko S., Hardie, Elizabeth A., Wakimoto, Ryutaro and Kashima, Yoshihisa. 2001. "Culture and gender specific implications of relational and collective contexts on spontaneous self-descriptions," Journal of cross-cultural psychology, 42: 740-758.

Lent, Robert W., Brown, Stephen D. and Hackett, Gail. 2002. "Social cognitive career theory" In Career Choice and Development, edited by Brown Duane, 255-311. San Francisco: JosseyBass.

Linn, Margaret L., Sandifier, Richard and Stein, Shayna. 1985. "Effects of unemployment on mental and physical health," American Journal of Public Health, 75/5: 502-506.

Luke, Tom. 2011. "The development of self-concept." http://www.wisc-online.com/objects/ ViewObject.aspx?ID=OIC800.

Maddux, William W. and Yuki, Masaki. 2006. "The ripple effect: cultural differences in perception of consequences of things," Personality and social psychology bulletin, 32/5: 669-683. 
Modupe, Hasan Eeunice. 2010. "Emotional Intelligence And Self - Esteem As Predictors For Success In Teaching Practice Exercise," Academic Leadership Online Journal, 8/3.

Moore, Katherine and Waters, Lea E. 2001. "Coping with economic deprivation during unemployment," Journal of Economic Psychology, 22/4: 461-482.

Moreland, John R., Harren, Vincent A., Krimsky-Montague, Eileen and Howard E.Tinsley. 1979. "Sex role self-concept and career decision-making," Journal of Counseling Psychology, 26/4: 329-336.

Nolen-Hoeksema, Susan. 2001. "Gender differences in depression," Current directions in psychlogical science 10/5: 173-176.

Peralta Sanchez, Francisco J. and Sanchez Roda, Maria D. 2003. "Relationships between selfconcept and academic achievements in primary students," Electronic Journal of Research in Educational Psychology and Psychopedagogy, 1/1: 95-120.

Piccinelli, Marco and Wilkinson, Greg. 2000. "Gender differences in depression." The British Journal of Psychiatry, 177: 486-492.

Powell, Katherine C. 2009. "The Role of Concept of Self and Societal Expectations Academic and Career Achievement," Journal of Adult Education, 38/2: 32-40.

Redman, Tom and Snape, Ed. 2006. "The Consequences of Perceived Age Discrimination Amongst Older Police Officers: Is Social Support a Buffer?" British Journal of Management, 17/2: 167-175.

Robert, Franken. 1994. Human motivation. Pacific Grove: Brooks Cole, 1994.

Roscigno, Vincent, Mong, Sherry, Byron, Reginald and Tester, Griff. 2007. "Age discrimination, Social Closure and Employment," Social Forces 86/1: 313-334.

Sargeant, Malcolm. 2006. "Mandatory retirement age and age discrimination," Employee Relations, 26/2: 151-166.

Scwarz-Woelzl, Maria, Oblak, Mirjana and Healy, Mike. 2008. "Become an employer of choice. Take age out of recruitment decisions". Research part of the EU-project mature@eu-Supporting Employers Recruit-ing and Selecting Mature Aged Persons, funded by the Leonardo da Vinci Program. www.zsi.at/attach/matureateu_brochure.pdf.

Sebastian, Catherine, Burnett, Stephanie and Blakemore, Sarah-J. 2008. "Development of the self-concept during adolescence," Trends in Cognitive Sciences, 12/ 11: 441-446.

Smari, Jacob, Arason, Elvar, Hafsteinsson, Hafsteinn and Snorri, Ingimarsson. 1997. Unemployment, coping and psychological distress," Scandinavian Journal of Psychology, 38/2: 151156.

Smith, Melinda and Segal, Robert. "Job loss and unemployment stress." Last modified March 2013, http://www.helpguide.org/life/unemployment_job_loss_stress_coping_tips.htm.

Sowislo, Julia Friederike and Orth, Ulrich. 2013. "Does Low Self-Esteem Predict Depression and Anxiety? A Meta-Analysis of Longitudinal Studies," Psychological Bulletin 139/1: 213-240.

Tougas, Francine, Lagace, Martine, de la Sablonniere, Roxane and Kocum, Lucie. 2004. "A new approach to the link between identity and relative deprivation in the perspective of ageism and retirement," International Journal of Aging and Human Development, 59/1: 1-23. 
Tjaša Redek, Andrej Sušjan, Črt Kostevc

Wigfield, Allan, Battle, Ann, Keller, Lisa B. and Jacquelynne S. Eccles. 2002. "Sex differences in motivation, self-concept, career aspiration and career choice: implications for cognitive development". http://rcgd.isr.umich.edu/garp/articles/eccles02.pdf.

Winter, Mary. 1997. "Stress taking charge." lowa State University. http://www.extension.iastate. edu/Publications/PM1660l.pdf.

Zavod za zaposlovanje (Employment service of Slovenia). 2012. http://www.ess.gov.si/trg_dela/ trg_dela_v_stevilkah/registrirana_brezposelnost.

Zuckerman, Diana M. 1980. "Self-esteem, self-concept, and the life goals and sex-role attitudes of college students" Journal of Personality, 48/2: 149-162. 